\title{
Normative Data for Bone Mass in Healthy Term Infants from Birth to 1 Year of Age
}

\author{
Sina Gallo, ${ }^{1}$ Catherine A. Vanstone, ${ }^{1}$ and Hope A. Weiler ${ }^{1,2}$ \\ ${ }^{1}$ School of Dietetics and Human Nutrition, McGill University, 21111 Lakeshore Road, Ste-Anne-de-Bellevue, QC, Canada H9X 3 V9 \\ ${ }^{2}$ Human Nutritional Sciences, University of Manitoba, Winnipeg, MB, Canada R3T 2N2
}

Correspondence should be addressed to Hope A. Weiler, hope.weiler@mcgill.ca

Received 13 June 2012; Revised 25 August 2012; Accepted 26 August 2012

Academic Editor: E. M. Lewiecki

Copyright (C) 2012 Sina Gallo et al. This is an open access article distributed under the Creative Commons Attribution License, which permits unrestricted use, distribution, and reproduction in any medium, provided the original work is properly cited.

\begin{abstract}
For over 2 decades, dual-energy X-ray absorptiometry (DXA) has been the gold standard for estimating bone mineral density (BMD) and facture risk in adults. More recently DXA has been used to evaluate BMD in pediatrics. However, BMD is usually assessed against reference data for which none currently exists in infancy. A prospective study was conducted to assess bone mass of term infants ( 37 to 42 weeks of gestation), weight appropriate for gestational age, and born to healthy mothers. The group consisted of 33 boys and 26 girls recruited from the Winnipeg Health Sciences Center (Manitoba, Canada). Whole body (WB) as well as regional sites of the lumbar spine (LS 1-4) and femur was measured using DXA (QDR 4500A, Hologic Inc.) providing bone mineral content (BMC) for all sites and BMD for spine. During the year, WB BMC increased by $200 \%$ (76.0 \pm 14.2 versus $227.0 \pm 29.7 \mathrm{~g})$, spine BMC by $130 \%$ ( $2.35 \pm 0.42$ versus $5.37 \pm 1.02 \mathrm{~g})$, and femur BMC by $190 \%$ ( $2.94 \pm 0.54$ versus $8.50 \pm 1.84 \mathrm{~g})$. Spine BMD increased by $14 \%\left(0.266 \pm 0.044\right.$ versus $\left.0.304 \pm 0.044 \mathrm{~g} / \mathrm{cm}^{2}\right)$ during the year. This data, representing the accretion of bone mass during the first year of life, is based on a representative sample of infants and will aid in the interpretation of diagnostic DXA scans by researchers and health professionals.
\end{abstract}

\section{Introduction}

Bone diseases are being increasingly recognized as a problem which begins in early life. Dual-energy X-ray absorptiometry (DXA) is an ideal method for the accurate assessment of bone mineral content (BMC) in pediatrics as radiation exposure is low and scan time is fast [1]. Despite the advantages of the technology, DXA manufacturers have limited normal reference values available for pediatric use and none for infants. There is a lack of consensus in the research area regarding appropriate normative values for bone mineral content (BMC) of infants because of differences in age of infants, DXA manufacturers, and scan acquisition (Table 1). It is clear that no one study has published on normative data collected longitudinally during infancy that includes both whole body and regional assessments. For the accurate interpretation of DXA data, there is a need for individual values to be expressed in relation to normative data.

The International Society for Clinical Densitometry (ISCD) [2] supports the whole body and lumbar spine (LS) as the preferred scan sites in pediatrics. Regional scans of the spine may also be easier to obtain in infants and children because these are less sensitive to movement artefact because of the rapid scan acquisition and central image. Areal bone mineral density $(\mathrm{aBMD})$ measurements $\left(\mathrm{g} / \mathrm{cm}^{2}\right)$ are based on a number of assumptions by DXA programs and are misleading as area is a two-dimensional assessment that does not account for the three-dimensional structure of bone. However, volumetric BMD (vBMD) can be estimated using DXA with simple mathematical calculations that have been proposed to overcome the problem of areal BMD, by eliminating the effect of skeletal size [3]. Calculated vBMD in sexually mature and immature primates [4] and adult humans [5] agrees better with vBMD obtained from ash weight, the gold standard method of measuring true BMC, than aBMD. Thus, there remains a need for normal reference data of BMC as well as vBMD in healthy infants.

The objectives of this paper are to create a normative reference data set for infants between birth to $12 \mathrm{mo}$ of age for the (i) BMC of whole body as well as lumbar spine and 


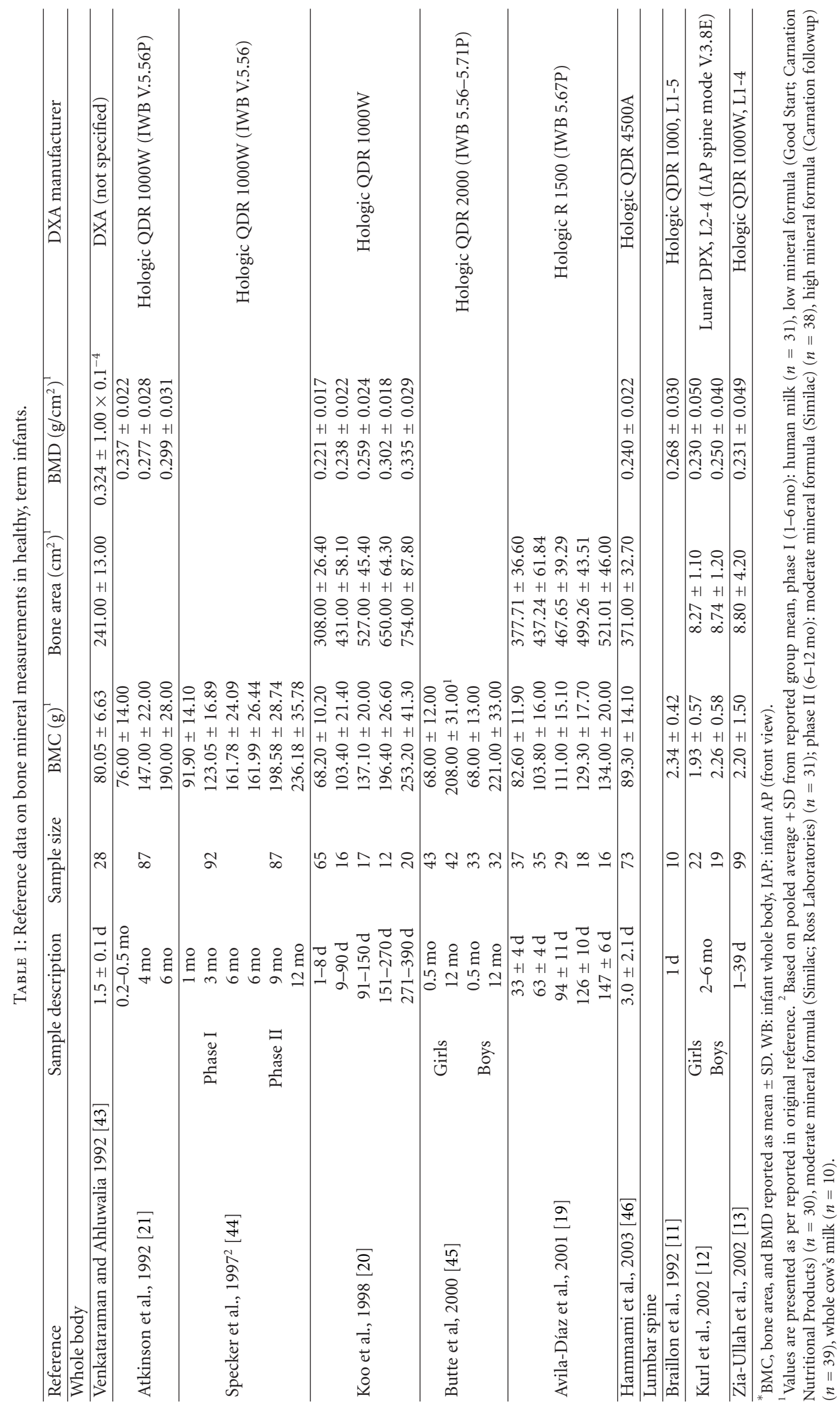


femur and (ii) aBMD and vBMD of the lumbar spine. This data will ultimately aid in the interpretation of bone scans in infants.

\section{Materials and Methods}

2.1. Study Subjects. Infants were recruited from the Health Sciences Center in Winnipeg, MB (latitude $49.54^{\circ} \mathrm{N}$ ), from births delivered between August 2001 and April 2003. For entry to the study, an infant had to be born between 37-42 weeks of gestation (based on ultrasound dating), appropriate birth weight for gestational age based on Center for Disease Control (CDC) 2000 growth charts (between 595th percentile), and free of congenital malformations. Cord blood and maternal blood (obtained at $0800 \mathrm{~h}$ within 48 hours of delivery) were collected into heparinized tubes, and plasma was separated from red blood cells (by centrifugation at $2000 \times \mathrm{g}$ ) followed by storage at $-80^{\circ} \mathrm{C}$ until analysis. Follow-up visits were conducted within 2-4 weeks of birth and at 6 and at $12 \mathrm{mo}$ of age. The total cohort involved 72 infants, but the current evaluation was limited to 63 infants ( 36 boys, 27 girls) who completed at least 2 of the 3 scheduled visits. At each visit, mothers were questioned about infant feeding practices (categorized as breastfed or formula fed) and supplement use (taking vitamin D supplement or any other infant multimineral/vitamin). Vitamin D supplements (Enfamil V-Di-Sol, $400 \mathrm{IU} / 1 \mathrm{~mL}$ ) or infant formula (Enfalac standard term) were provided in kind by Mead-Johnson depending on feeding type up to 1 year of age as per nutritional requirements (formula fed infants do not require vitamin D supplementation). Mothers were asked to self-identify their ethnicity, and season of birth was determined based on the solstices and equinoxes of the current calendar year. The study was approved by the ethical review board of the University of Manitoba Ethics Review Board (Manitoba, Canada), and informed consent was obtained for all participants.

2.2. Anthropometric and BMC Measurements. At follow-up visits, weight was taken to the nearest gram using an electronic scale (model SB 32000, Mettler-Toledo Inc., Greifensee, Switzerland), length to the nearest $0.1 \mathrm{~cm}$ using an infant length board (O'Learly Length Boards, Ellard Instrumentation Ltd., Seattle, WA), and head circumference to the nearest $0.1 \mathrm{~cm}$ using nonstretchable tape (Perspective Enterprises, Portage, MI). BMC of the whole body, lumbar spine (vertebrae 1-4), and femur was assessed by a certified bone densitometry technologist. Infants were scanned in array mode by DXA (QDR 11.2, QDR 4500A Elite, Hologic Inc., Waltham, MA) for infant whole body software, anterior posterior lumbar spine for vertebrae 1 to 4 using the AP spine software, and femur using left hip subregion analysis. While the lumbar spine scan is akin to that of adults, the femur scan was of the whole femur from proximal to distal epiphyses and analyzed as a whole bone to derive whole femur BMC. The auto low density option was used for both spine and femur detection and bone maps were manually traced. All scans were independently reviewed by two certified bone densitometry technologists. Scans were typically performed in the following order: whole body, lumbar spine, and the left femur. To limit error, infants were scanned while asleep in order to minimize the potential for movement artefact and maximize the probability that both regional and whole body scans be performed with the infant in the same position. For all analyses, scans were not used if $>2$ line breaks were observed or if the infant was positioned on his/her side or stomach although the errors obtained in altered positioning are considered small [6]. Each infant wore a single light sleeper with no metal or plastic components and a diaper; infants were wrapped in a single receiving blanket. BMC was expressed as absolute weight in grams. Areal BMD was calculated for lumbar spine by the DXA software as BMC divided by projected area of the scan. Volumetric BMD was calculated using the Carter method [3] as aBMD divided by the square root of the projected area. The CV for quality control measurements of BMC using a spine phantom (Hologic phantom number 8832) over the course of the study was $<1.0 \%$. This same DXA machine was used as part of the Canadian Steroid-Associated Osteoporosis in the Pediatric Population (STOPP) study [7] which involved 10 tertiary children's care centers across Canada between 2005 and 2007. A spine phantom (number S5550) was cross-calibrated across study sites including the Manitoba Child Institute of Child Health, and in vivo precision for LS BMD ranged from 0.003 to $0.0173 \mathrm{~g} / \mathrm{cm}^{2}$.

2.3. Vitamin $D$ Measurements. To further describe the cohort, vitamin D was measured as 25 -hydroxyvitamin D $(25(\mathrm{OH}) \mathrm{D})$ in cord plasma in duplicates using a radioimmunoassay (Diasorin, Stillwater, MN). The assay was run in accordance with manufacturer's specifications, with a coefficient of variation less than $10 \%$. The vitamin D status of mothers and infants was categorized as deficient based on a plasma $25(\mathrm{OH}) \mathrm{D}$ concentration less than $37.5 \mathrm{nmol} / \mathrm{L}$ for mothers and less than $27.5 \mathrm{nmol} / \mathrm{L}$ for infants $[8,9]$.

2.4. Sample Size Estimations. The primary objective of this report is to describe the bone mass of infants over the first year of life; thus, given our available sample size, the desired total width (margin of error) was estimated between the observed mean and the population mean. The desired sample total width was based on the following calculation: $W^{2}=4 z_{\alpha}^{2} S^{2} / n$ [10], where $z_{\alpha}^{2}=95 \%$ confidence level, $S=$ standard deviation of spine bone mineral density from previous studies (based on $0.132 \mathrm{~g} / \mathrm{cm}^{2}$ ) [11-13], and $W=$ width of the margin of error. Based on our sample size of 63 infants, we are $95 \%$ confident that the true mean spine bone mineral density of sampled infants is within $6.5 \%$ of the true population mean. However, the width of the confidence interval for LS BMC (based on standard deviation of $0.77 \mathrm{~g}$ ) was within $38 \%$ of the true population mean, and to decrease the margin of error to within $15 \%$, the sample size would need to increase to 405 infants.

2.5. Statistical Analyses. Descriptive results for continuous variables are expressed as arithmetic mean $( \pm S D)$. All BMC measurements were considered as continuous variables, and differences compared among sex, feeding mode, and season of birth were tested using Student's $t$-test at each time 
point. Differences in bone parameters over time were tested by one-way analysis of variance (ANOVA) with the Tukey adjustment for multiple comparisons. Statistical significance was set at $P \leq 0.05$, and all $P$ values presented are two tailed. Data was analyzed using Statistical Analysis System (SAS) version 9.2 statistical software (SAS Institute Inc., Cary, NC). A reference curve was generated for lumbar spine BMD using the "LMS" method [14]. The curve was constructed using LMS Chartmaker Pro (version 2.54; T Cole \& H Pan, copyright 1997-2006, Medical Research Council, UK). The LMS method fits 3 parameters (LMS) as cubic splines by nonlinear regression $[14,15]$. The 3 parameters represent the median $(M), \mathrm{SD}(S)$, and power in the Box-Cox transformation $(L)$ that vary as a function of age using the following formula: $\mathrm{BMD}$ centile $=M(1+L \cdot S \cdot Z) 1 / L[14,15]$, where $L, M, S$ are age-specific and $Z$ is the $Z$-score that corresponds to a given percentile. Fit of the curves was evaluated by graphical inspection of the curves relative to the raw data and by $Q-Q$ plots.

\section{Results}

3.1. Subject Characteristics. Subject and maternal characteristics are presented in Table 2. At birth, the mean gestational age of infants was $39( \pm 1)$ wk and weight-for-age percentile was $52.1( \pm 26.4)$ in accordance with inclusion criteria. Based on self-reports, approximately $29 \%$ of infants were formula fed from birth, $49 \%$ were breastfed for less than $6 \mathrm{mo}$, and $22 \%$ were breastfed for longer than 6 mo. Mother's age at birth was $28( \pm 6)$ y. The majority of mothers self-identified their race as being white (65\%), 16\% were of First Nations status, 3\% were black, and the remainder were of other ethnicity (Hispanic, East Asian, etc.). Season of birth was equally divided among all participants, 51\% of infants were born during the summer/fall, and $49 \%$ were born during the winter/spring months. Plasma $25(\mathrm{OH}) \mathrm{D}$ was $<27.5 \mathrm{nmol} / \mathrm{L}$ in $19(30 \%)$ infants and $<37.5 \mathrm{nmol} / \mathrm{L}$ in $23(37 \%)$ mothers.

3.2. Bone Mineral Content. Mean BMC of whole body, lumbar spine, and femur at term and 6 and 12 mo is shown in Table 3. There was a rapid increase of $123 \%$ in whole body BMC up to 6 mo from term $(P<0.01)$, and this rate slows to a $34 \%$ increase from 6 to 12 mo of age. There were significant sex differences for whole body BMC noted at 6 mo of age $(P<0.01)$ between boys $(184.49 \pm 27.09 \mathrm{~g})$ and girls $(149.46 \pm 17.22 \mathrm{~g})$ which disappeared at 12 mo of age. Femur BMC grows rapidly from 6 mo of age (at an increase of $90 \%$ from term to $6 \mathrm{mo}$ and $52 \%$ from 6 to $12 \mathrm{mo}$ ), whereas spine BMC increases more linearly over the first year. Significant differences were observed between boys $(3.81 \pm 0.59 \mathrm{~g}$; $5.65 \pm 1.03 \mathrm{~g})$ and girls $(3.30 \pm 0.56 \mathrm{~g} ; 5.02 \pm 0.91 \mathrm{~g})$ at both $6(P<0.01)$ and $12 \mathrm{mo}(P<0.05)$, respectively, for spine BMC. Similarly, there were significant differences between boys $(8.97 \pm 1.79 \mathrm{~g})$ and girls $(7.90 \pm 1.75 \mathrm{~g})$ at $12 \mathrm{mo}(P<$ $0.05)$ for femur BMC. There were significant differences $(P<$ $0.05)$ in spine BMC at both 6 and 12 mo between infants which were formula fed $(3.81 \pm 0.63 \mathrm{~g} ; 5.79 \pm 0.90 \mathrm{~g})$ and those breastfed for at least $1 \mathrm{mo}(3.48 \pm 0.60 \mathrm{~g} ; 5.18 \pm 1.02 \mathrm{~g})$, respectively, but no differences were detected in femur BMC
TABLE 2: Infant and maternal characteristics.

\begin{tabular}{|c|c|}
\hline Characteristic & Mean $( \pm$ SD $)$ \\
\hline Gestational age, weeks & $39.3 \pm 1.1$ \\
\hline $\begin{array}{l}\text { Weight-for-age percentile } \\
\text { (CDC } 2000 \text { growth charts) }\end{array}$ & $52.1 \pm 26.4$ \\
\hline $\begin{array}{l}\text { Feeding type, } n(\%) \\
\quad \text { Formula }\end{array}$ & $18(28.6)$ \\
\hline Breastfeed $<6 \mathrm{mo}^{\psi}$ & $31(49.2)$ \\
\hline Breastfeed $>6 \mathrm{mo}$ & $14(22.2)$ \\
\hline \multicolumn{2}{|l|}{ Season of birth, $n(\%)$} \\
\hline Summer/fall & $32(50.8)$ \\
\hline Winter/spring & $31(49.2)$ \\
\hline \multicolumn{2}{|l|}{ Infant's vitamin D status } \\
\hline Deficient $^{1}$ & $19(30.2)$ \\
\hline Sufficient & $44(69.8)$ \\
\hline Mother's age at birth, years & $27.7 \pm 6.1$ \\
\hline \multicolumn{2}{|l|}{ Mother's race, $n(\%)$} \\
\hline White & $41(65.1)$ \\
\hline First nations & $10(15.9)$ \\
\hline Asian & $7(11.1)$ \\
\hline Black & $2(3.2)$ \\
\hline Other & $3(4.8)$ \\
\hline \multicolumn{2}{|l|}{ Mother's vitamin D status } \\
\hline Deficient $^{2}$ & $23(36.5)$ \\
\hline Sufficient & $40(63.5)$ \\
\hline $\begin{array}{l}\text { Infant: } 25(\mathrm{OH}) \mathrm{D} \leq 27.5 \mathrm{nmo} \\
\text { Institute of medicine dietary refe } \\
\text { breastfeeding and mixed feeding } \\
\text { receiving only breast milk witho }\end{array}$ & $\begin{array}{l}37.5 \mathrm{nmol} / \mathrm{L}- \\
\text { nclude exclusive } \\
\text { fers to an infant } \\
\text { food. }\end{array}$ \\
\hline
\end{tabular}

by feeding mode. As well, there were differences noted in both spine BMC at term by season of birth; spring babies had higher $(P<0.05)$ spine BMC $(2.51 \pm 0.39 \mathrm{~g})$ than fall babies $(2.07 \pm 0.33 \mathrm{~g})$. These differences did not persist at 6 and 12 mo of age. Ethnicity and race differences were not considered because of the limited number of participants in each category.

3.3. Spine Bone Mineral Density. Mean BMD of lumbar spine at term and 6 and $12 \mathrm{mo}$ is shown in Table 3. Spine BMD decreased by $5 \%$ from term to 6 mo of age and then increased by $21 \%$ from 6 to 12 mo of age. No significant differences were noted at each time point according to sex or infant's vitamin D status at birth (deficient/sufficient). However, there were significant differences $(P<0.01)$ in spine $\mathrm{BMD}$ at the 12 mo time point between infants which were formula fed $\left(0.328 \pm 0.040 \mathrm{~g} / \mathrm{cm}^{2}\right)$ and those breastfed $\left(0.293 \pm 0.043 \mathrm{~g} / \mathrm{cm}^{2}\right)$. As well, spring babies had higher $(P<0.05)$ spine BMD $\left(0.290 \pm 0.038 \mathrm{~g} / \mathrm{cm}^{2}\right)$ than fall babies $\left(0.248 \pm 0.037 \mathrm{~g} / \mathrm{cm}^{2}\right)$. The final smoothed percentile curve for spine aBMD is shown in Figure 1 depicting the 3, 10, 25, $50,75,90$, and 97 th percentiles.

Volumetric BMD was calculated for lumbar spine (Table 3). During the first $6 \mathrm{mo}$, there appears to be a decrease in vBMD followed by stabilization up to $12 \mathrm{mo}$. 
TABLE 3: Mean \pm SD $(n)$ bone mineral content of whole body, femur, lumbar spine, and bone area, areal bone mineral density, and volumetric bone mineral density of the lumbar spine from birth to $12 \mathrm{mo}$ of age in term infants. Means with different superscript letters indicate statistically significant differences between time points $(P<0.05$, post-Tukey adjustment).

\begin{tabular}{|c|c|c|c|c|c|c|}
\hline Site & Term & & $6 \mathrm{mo}$ & & $12 \mathrm{mo}$ & \\
\hline Total WB BMC, g & $75.98 \pm 14.17^{\mathrm{a}}$ & $(52)$ & $169.48 \pm 29.01^{\mathrm{b}}$ & (35) & $227.0 \pm 29.73^{c}$ & $(11)$ \\
\hline Total WB BMC/body weight, g/kg & $20.71 \pm 2.49^{a}$ & $(52)$ & $21.41 \pm 1.89^{\mathrm{a}}$ & $(35)$ & $23.39 \pm 1.17^{\mathrm{b}}$ & $(11)$ \\
\hline WB BMC less head, $g$ & $43.58 \pm 8.13^{\mathrm{a}}$ & $(52)$ & $87.66 \pm 16.32^{\mathrm{b}}$ & $(35)$ & $114.8 \pm 21.86^{\mathrm{c}}$ & $(11)$ \\
\hline WB BMC less head/body weight, g/kg & $11.89 \pm 1.59^{\mathrm{a}}$ & $(52)$ & $11.04 \pm 1.08^{\mathrm{b}}$ & $(35)$ & $11.75 \pm 0.75^{\mathrm{a}, \mathrm{b}}$ & $(11)$ \\
\hline Femur BMC, g & $2.94 \pm 0.54^{\mathrm{a}}$ & $(61)$ & $5.58 \pm 1.46^{\mathrm{b}}$ & $(60)$ & $8.50 \pm 1.84^{\mathrm{c}}$ & $(54)$ \\
\hline Lumbar spine BMC, $g$ & $2.35 \pm 0.42^{\mathrm{a}}$ & $(62)$ & $3.59 \pm 0.63^{b}$ & $(62)$ & $5.37 \pm 1.02^{\mathrm{c}}$ & $(57)$ \\
\hline Lumbar spine area, $\mathrm{cm}^{2}$ & $8.86 \pm 1.10^{\mathrm{a}}$ & $(62)$ & $14.28 \pm 2.01^{\mathrm{b}}$ & $(62)$ & $17.67 \pm 2.52^{\mathrm{c}}$ & $(57)$ \\
\hline Lumbar spine areal BMD, $\mathrm{g} / \mathrm{cm}^{2}$ & $0.266 \pm 0.044^{\mathrm{a}}$ & $(62)$ & $0.252 \pm 0.031^{\mathrm{a}}$ & $(62)$ & $0.304 \pm 0.044^{\mathrm{b}}$ & $(57)$ \\
\hline Lumbar spine volumetric BMD, $\mathrm{g} / \mathrm{cm}^{3}$ & $0.090 \pm 0.017^{\mathrm{a}}$ & $(62)$ & $0.067 \pm 0.010^{\mathrm{b}}$ & $(62)$ & $0.073 \pm 0.012^{\mathrm{b}}$ & $(57)$ \\
\hline
\end{tabular}

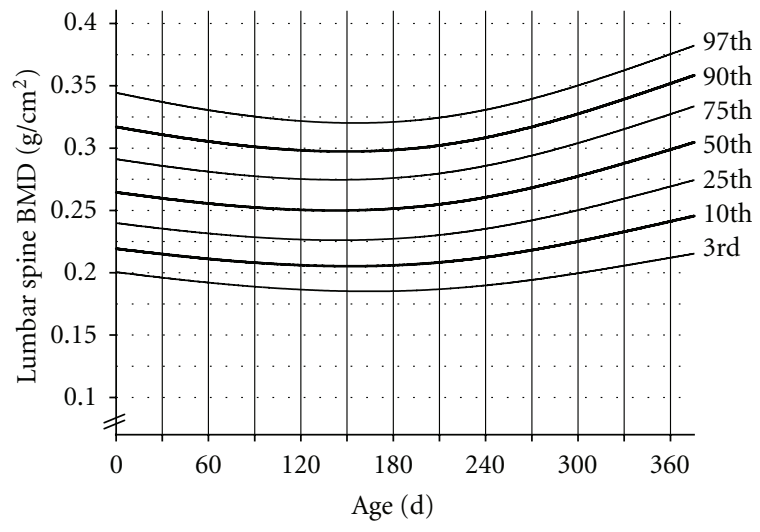

FIGURE 1: Spine BMD-for-age reference curve for infants, birth to 12 mo.

The spine vBMD measurement was not subject to gender differences, as well, there were no differences according to infant's vitamin D status at birth. Similar to aBMD, there were significant differences $(P<0.05)$ in spine vBMD at 12 mo between infants which were formula fed $(0.079 \pm$ $\left.0.01 \mathrm{~g} / \mathrm{cm}^{3}\right)$ and those breastfed $\left(0.070 \pm 0.01 \mathrm{~g} / \mathrm{cm}^{3}\right)$.

\section{Discussion}

The ISCD recommends spine and whole body as the preferred scan sites for the diagnosis of bone diseases in children $[2,16]$; however, presently no specific recommendations exist for infants. In infants, the head can represent up to $50 \%$ of total BMC, and due to inaccuracies in the algorithm for determining skull BMC [17], the use of the whole body less head measurement may be preferred. As infants grow, it becomes increasingly difficult for them to fall asleep on the DXA bed making the whole body assessment challenging to attain because of movement artefact. The challenge is even greater when you have a child with contractures, mental impairment, or other impediments to scanning which is of importance as these children may have conditions which predispose them to low bone density [18]. Observations from previous research utilizing pediatric DXA had similar sample size reductions with increasing age $[19,20]$. In one study, movement artefact was reported in $20 \%$ of infants scanned rendering the whole body scan unusable [20]. While our data for whole body BMC is robust up to $6 \mathrm{mo}$, it is not reliable beyond the 6 mo time point because of our limited sample size due to movement artefact. The data on whole body BMC up to 6 mo was consistent with previous researchers who tracked 87 term infants until 6 mo [21]. Due to the variability in obtaining a scan for whole body measurements, regional sites may have more clinical utility. Although data is available for spine measurements using DXA, the previously published data consist mostly of cross-sectional studies. Thus, this present work provides much needed data on healthy infants followed longitudinally in the first year of life.

Lumbar spine vertebra is the easiest measurement site to obtain in infants because it is less subject to movement artefact while providing minimal effective dose of radiation [22]. Although validation studies for the lumbar spine are not available on the QDR 4500A, precision for lumbar spine measurements in infants has also been reported to be good in an older model with a coefficient of variation of $2.4 \%$ and $1.55 \%$ for BMC and BMD, respectively [11]. In addition, spine is formed mainly by trabecular bone, and the rate of bone turnover in the trabecular compartment is much more rapid than in the cortical area, thus, allowing for better tracking of bone changes in clinical trials. Thus, rates of change in bone density will be greater in sites that are predominately trabecular bone such as the spine. The previous literature on lumbar spine bone mineral mass is inconsistent because of the use of different vertebrae for analysis; however, the most recent publications have focused on lumbar vertebrae $1-4[13,23]$. While spine BMC is the most easily obtained measurement, it seems to have the lowest rate of accretion over the first year. Even for BMD, increments were only 14\% suggesting that growth and mineral accretion is lower during this time compared to the long bones.

Not much is known about infant femur BMC, and this study provides extended knowledge in this area. Cortical bone mass is lower in infants born small-for-gestational-age compared to appropriate-for-gestational-age infants [24]. Although DXA cannot distinguish between cortical and trabecular bone mass, the content of cortical bone is higher in the femur than in the spine. Interestingly, Weiler et al. [25] found premature infants born with very low birth weight $(\leq 1200 \mathrm{~g})$ who were supplemented with early minimal 
enteral feeds had higher elevations in femur bone mass (36\%) compared to spine bone mass (16\%). In these infants [25], femur responded to a greater extent than spine and may prove valuable in assessing response to treatment. In addition, Lu et al. [26] observed that vBMD of the femur and not the lumbar spine was less dependent on growth variables in their study with children and young adults.

The Carter method for the calculation of vBMD has been widely used in adults [27-29] and is being increasingly recognized for use with children $[30,31]$. Much of this data has been derived from pencil beam DXA systems [27, 29], and new fan-beam systems have shown improvements over pencil beam technology [32, 33]. However, the objective of reporting this calculated value using our dataset was to provide reference data for those clinicians who favor this approach while acknowledging that validation studies have found conflicting results. In cadavers of older adults, vBMD was estimated from an equation similar to the Carter method and was strongly correlated with true vBMD calculated by dividing ash weight by CT-derived volume $\left(r^{2}=0.94\right)$ [34]. In children and adolescents, volumetric adjustments improved only slightly the correlation with CT-measured $\operatorname{vBMD}\left(r^{2}=0.13\right.$ and 0.60 from $r^{2}=0.02$ and 0.51 in Tanner stages 1-3 and 4-5, resp.) [35]. Although this method has been used in infancy [35], it has not been validated in this population group. It has been suggested that, using an average of anterior posterior (AP), lumbar spine and lateral vertebral scans can approximate vBMD because it makes assessments of vertebral height, width, and depth. Even in infants with osteopetrosis, which causes an increase in bone mass, the average AP and lateral spine measurements correlated well with CT measures of BMD $\left(r^{2}=0.851, P<0.001\right)$ [36]. In an older group, a comparison of paired AP lateral spine and estimated vBMD using the Carter method found a significant correlation of $r=0.81$ [37]. Although considered indirectly, this implies that estimated vBMD values show promise even though this remains to be directly validated against CT in infants. In our study, spine vBMD decreases during the first 6 mo because this is a period of rapid bone modeling and the bone is mineralizing at a slower rate than the bone is growing. This is a normal phenomenon as previously observed [38] and is not a sign of bone loss. The mineralization starts to catch up by $6 \mathrm{mo}$, and vBMD remains fairly stable up to 12 mo. Volumetric BMD of the spine may become a preferred assessment site because it is also not subject to gender differences in infancy.

Percentile curves for growth have been widely used to assess the nutritional status and general health of infants, children, and adolescents. Bone mass data assessed by DXA is limited in healthy, term infants, and at present there is no available data that presents normative bone mass measurements for infants using percentile charts. The percentile chart that was constructed for spine bone mineral density is displayed to show a possible alternative way to illustrate normative data. Presenting data in this manner will help health care professionals and clinical researchers plot infants and compare to healthy infants of the same age and gender, thus determining adequacy. Larger datasets using prospectively collected data can be utilized in the same manner [14]. Mode of infant feeding can have an important influence on growth and body composition [39]. Our data corroborate these findings as we found that being formula fed had a significant effect on the aBMD of the spine by 12 mo of age. The differences in bone mass noted between sexes may be related to differences in growth as anthropometric characteristics were significantly different at each time point; however, there were no growth differences between the feeding groups. According to Statistics Canada's 2003 Canadian Community Health Survey (CCHS) [40], approximately $85 \%$ of Canadian women attempted breastfeeding and $47 \%$ did so for longer than 6 mo. In our group, approximately 71\% were breast fed for at least 1 mo of age of which 31\% were breastfeeding for longer than 6 mo. Therefore, the present data set provides a representative sample of breast-fed and formula-fed infants in keeping with current Canadian statistics. Although a vitamin D supplement was provided to all participating breastfeeding mothers in this study, compliance data was selfreported. An optimal growth reference should be based on a group of healthy, breast-fed infants receiving vitamin D supplementation.

There are limitations with this data because it is not based on a nationally representative sample and observations were recorded at 6 mo intervals during the first year. Infants were recruited solely from Winnipeg, $\mathrm{MB}$, which is located at the 49th parallel north and in south central Canada. Nonetheless, our results were similar to those obtained in southern Ontario [21]. Furthermore, the prevalence of maternal vitamin $\mathrm{D}$ deficiency from this group was similar to that reported from other Canadian studies [41, 42]. Future research should seek pooled data from cross country sites with observations recorded at $1-3$ mo intervals to create a combined bone mass percentile chart data set.

In summary, DXA is a valuable tool for the screening and diagnosis of pediatric bone diseases. This data provides the foundation for future research, but also provides important reference data not currently available, for infants on femur BMC and vBMD. This in addition to clinical data will ultimately aid in the diagnosis, interpretation, and response to treatment for pediatric bone diseases.

\section{Acknowledgments}

This work was supported by a grant from the Canadian Institutes of Health Research. S. Gallo was the primary author for the paper. S. Gallo performed statistical analyses and made major data interpretations. C. A. Vanstone conducted analyses of all DXA scans. H. A. Weiler provided assistance with the implementation of the study as well as consultation for statistical analyses and data interpretations. $\mathrm{H}$. A. Weiler and C. A. Vanstone provided editorial revisions for the paper. H. A. Weiler was the principal investigator for the research project and provided access to the study database. None of the authors had any financial or personal conflicts of interests. These results were presented in part at the 2008 Experimental Biology conference (San Diego, CA). The authors wish to thank Mrs. Shirley C. Fitzpatrick-Wong and Mrs. Jeannine M. Schellenberg for their help with data collection as well as the Newborn Units at the Women's 
Hospital (Winnipeg, MB) and the research group at University of Manitoba (R. Veitch, H. Kovacs, U. McCloy, D. Fair) for their help with interviews and coordination of the study.

\section{References}

[1] S. Mora, L. Bachrach, and V. Gilsanz, "Noninvasive techniques for bone mass measurement," in Pediatric Bone: Biology and Diseases, F. Glorieux, J. Pettifor, and H. Juppner, Eds., pp. 303324, Academic Press, San Diego, Calif, USA, 2003.

[2] N. Binkley, J. P. Bilezikian, D. L. Kendler, E. S. Leib, E. M. Lewiecki, and S. M. Petak, "Official Positions of the International Society for Clinical Densitometry and Executive Summary of the 2005 Position Development Conference," Journal of Clinical Densitometry, vol. 9, no. 1, pp. 4-14, 2006.

[3] D. R. Carter, M. L. Bouxsein, and R. Marcus, "New approaches for interpreting projected bone densitometry data," Journal of Bone and Mineral Research, vol. 7, no. 2, pp. 137-145, 1992.

[4] S. M. Ott, M. O’Hanlan, E. W. Lipkin, and L. Newell-Morris, "Evaluation of vertebral volumetric versus areal bone mineral density during growth," Bone, vol. 20, no. 6, pp. 553-556, 1997.

[5] M. A. Sabin, G. M. Blake, S. M. MacLaughlin-Black, and I. Fogelman, "The accuracy of volumetric bone density measurements in dual X-ray absorptiometry," Calcified Tissue International, vol. 56, no. 3, pp. 210-214, 1995.

[6] R. C. Henderson, R. K. Lark, J. B. Renner et al., "Dual X-ray absorptiometry assessment of body composition in children with altered body posture," Journal of Clinical Densitometry, vol. 4, no. 4, pp. 325-335, 2001.

[7] J. Halton, I. Gaboury, R. Grant et al., "Advanced vertebral fracture among newly diagnosed children with acute lymphoblastic leukemia: results of the Canadian Steroid-Associated Osteoporosis in the Pediatric Population (STOPP) research program," Journal of Bone and Mineral Research, vol. 24, no. 7, pp. 1326-1334, 2009.

[8] IOM (Institute of Medicine), Dietary Reference Intakes for Calcium, Phosphorus, Magnesium, Vitamin D, and Fluoride, The National Academies Press, Washington, DC, USA, 1997.

[9] IOM (Institute of Medicine), Dietary Reference Intakes for Calcium and Vitamin D, The National Academies Press, Washington, DC, USA, 2011.

[10] W. Browner, S. R. Cummings, S. B. Hulley, and T. B. Newman, "Estimating sample size and power: the nitty-gritty," in Designing Clinical Research: An Epidemiologic Approach, S. Hulley, Ed., Lippincott Williams and Wilkins, Philadelphia, Pa, USA, 2001.

[11] P. M. Braillon, B. L. Salle, J. Brunet, F. H. Glorieux, P. D. Delmas, and P. J. Meunier, "Dual energy x-ray absorptiometry measurement of bone mineral content in newborns: validation of the technique," Pediatric Research, vol. 32, no. 1, pp. 77-80, 1992.

[12] S. Kurl, K. Heinonen, J. S. Jurvelin, and E. Länsimies, "Lumbar bone mineral content and density measured using a Lunar DPX densitometer in healthy full-term infants during the first year of life," Clinical Physiology and Functional Imaging, vol. 22, no. 3, pp. 222-225, 2002.

[13] M. Zia-Ullah, W. W. K. Koo, and M. Hammami, "Lumbar spine bone measurements in infants: whole-body vs lumbar spine dual X-ray absorptiometry scans," Journal of Clinical Densitometry, vol. 5, no. 1, pp. 17-25, 2002.
[14] T. J. Cole and P. J. Green, "Smoothing reference centile curves: the LMS method and penalized likelihood," Statistics in Medicine, vol. 11, no. 10, pp. 1305-1319, 1992.

[15] B. S. Zemel, V. A. Stallings, M. B. Leonard et al., "Revised pediatric reference data for the lateral distal femur measured by Hologic Discovery/Delphi dual-energy X-ray absorptiometry," Journal of Clinical Densitometry, vol. 12, no. 2, pp. 207218, 2009.

[16] C. M. Gordon, L. K. Bachrach, T. O. Carpenter et al., "Dual energy X-ray absorptiometry interpretation and reporting in children and adolescents: the 2007 ISCD pediatric official positions," Journal of Clinical Densitometry, vol. 11, no. 1, pp. 43-58, 2008.

[17] A. Taylor, P. T. Konrad, M. E. Norman, and H. T. Harcke, "Total body bone mineral density in young children: influence of head bone mineral density," Journal of Bone and Mineral Research, vol. 12, no. 4, pp. 652-655, 1997.

[18] E. A. Szalay and D. Harriman, "Adapting pediatric DXA scanning to clinical orthopaedics," Journal of Pediatric Orthopaedics, vol. 26, no. 5, pp. 686-690, 2006.

[19] M. Avila-Díaz, S. Flores-Huerta, I. Martínez-Muñiz, and D. Amato, "Increments in whole body bone mineral content associated with weight and length in pre-term and full-trerm infants during the first 6 months of life," Archives of Medical Research, vol. 32, no. 4, pp. 288-292, 2001.

[20] W. W. K. Koo, A. J. Bush, J. Walters, and S. E. Carlson, "Postnatal development of bone mineral status during infancy," Journal of the American College of Nutrition, vol. 17, no. 1, pp. 6570, 1998.

[21] S. Atkinson et al., "Pattern of growth and body composition in premature compared to term infants from term to six months," The FASEB Journal, vol. 8, p. A278, 1994.

[22] S. R. Thomas, H. J. Kalkwarf, D. D. Buckley, and J. E. Heubi, "Effective dose of dual-energy X-ray absorptiometry scans in children as a function of age," Journal of Clinical Densitometry, vol. 8, no. 4, pp. 415-422, 2005.

[23] C. M. Smith, R. C. Coombs, A. T. Gibson, and R. Eastell, "Adaptation of the Carter method to adjust lumbar spine bone mineral content for age and body size: application to children who were born preterm," Journal of Clinical Densitometry, vol. 9, no. 1, pp. 114-119, 2006.

[24] J. Palacios, S. Rodriguez, and J. I. Rodriguez, "Intra-uterine long bone growth in small-for-gestational-age infants," European Journal of Pediatrics, vol. 151, no. 4, pp. 304-307, 1992.

[25] H. A. Weiler, S. C. Fitzpatrick-Wong, J. M. Schellenberg et al., "Minimal enteral feeding within $3 \mathrm{~d}$ of birth in prematurely born infants with birth weight $\leq 1200 \mathrm{~g}$ improves bone mass by term age," American Journal of Clinical Nutrition, vol. 83, no. 1, pp. 155-162, 2006.

[26] P. W. Lu, C. T. Cowell, S. A. Lloyd-Jones, J. N. Briody, and R. Howman-Giles, "Volumetric bone mineral density in normal subjects, aged 5-27 years," Journal of Clinical Endocrinology and Metabolism, vol. 81, no. 4, pp. 1586-1590, 1996.

[27] S. Cvijetić and M. Koršić, "Apparent bone mineral density estimated from DXA in healthy men and women," Osteoporosis International, vol. 15, no. 4, pp. 295-300, 2004.

[28] E. D. Daniels, J. M. Pettifor, C. M. Schnitzler, G. P. Moodley, and D. Zachen, "Differences in mineral homeostasis, volumetric bone mass and femoral neck axis length in black and white South African women," Osteoporosis International, vol. 7, no. 2, pp. 105-112, 1997.

[29] S. Khosla, E. J. Atkinson, B. L. Riggs, and L. J. Melton, "Relationship between body composition and bone mass in 
women," Journal of Bone and Mineral Research, vol. 11, no. 6, pp. 857-863, 1996.

[30] L. A. Binkovitz, M. J. Henwood, and P. Sparke, "Pediatric DXA: technique, interpretation and clinical applications," Pediatric Radiology, vol. 38, supplement 2, pp. S227-S239, 2008.

[31] V. Gilsanz and T. Wren, "Assessment of bone acquisition in childhood and adolescence," Pediatrics, vol. 119, supplement 2, pp. S145-S149, 2007.

[32] P. Tothill, W. J. Hannan, and S. Wilkinson, "Comparisons between a pencil beam and two fan beam dual energy X-ray absorptiometers used for measuring total body bone and soft tissue," British Journal of Radiology, vol. 74, no. 878, pp. 166176, 2001.

[33] R. J. Toombs, G. Ducher, J. A. Shepherd, and M. J. De Souza, "The impact of recent technological advances on the trueness and precision of DXA to assess body composition," Obesity, vol. 20, no. 1, pp. 30-39, 2012.

[34] M. M. Sran, K. M. Khan, K. Keiver, J. B. Chew, H. A. McKay, and T. R. Oxland, "Accuracy of DXA scanning of the thoracic spine: cadaveric studies comparing BMC, areal BMD and geometric estimates of volumetric BMD against ash weight and CT measures of bone volume," European Spine Journal, vol. 14, no. 10, pp. 971-976, 2005.

[35] T. A. L. Wren, X. Liu, P. Pitukcheewanont, and V. Gilsanz, "Bone acquisition in healthy children and adolescents: comparisons of dual-energy X-ray absorptiometry and computed tomography measures," Journal of Clinical Endocrinology and Metabolism, vol. 90, no. 4, pp. 1925-1928, 2005.

[36] S. C. Kaste, K. A. Kasow, and E. M. Horwitz, "Quantitative bone mineral density assessment in malignant infantile osteopetrosis," Pediatric Blood and Cancer, vol. 48, no. 2, pp. 181$185,2007$.

[37] M. B. Leonard, J. Shults, and B. S. Zemel, "DXA estimates of vertebral volumetric bone mineral density in children: potential advantages of paired posteroanterior and lateral scans," Journal of Clinical Densitometry, vol. 9, no. 3, pp. 265273, 2006.

[38] F. Rauch and E. Schoenau, "Changes in bone density during childhood and adolescence: an approach based on bone's biological organization," Journal of Bone and Mineral Research, vol. 16, no. 4, pp. 597-604, 2001.

[39] N. F. Butte, W. W. Wong, J. M. Hopkinson, E. Smith, and K. J. Ellis, "Infant feeding mode affects early growth and body composition,” Pediatrics, vol. 106, no. 6, pp. 1355-1366, 2000.

[40] W. Millar and H. Maclean, "Breastfeeding practices," Health Reports, vol. 16, no. 2, pp. 23-31, 2005.

[41] D. Rucker, J. A. Allan, G. H. Fick, and D. A. Hanley, "Vitamin D insufficiency in a population of healthy western Canadians," Canadian Medical Association Journal, vol. 166, no. 12, pp. 1517-1524, 2002.

[42] R. Vieth, D. E. Cole, G. A. Hawker, H. M. Trang, and L. A. Rubin, "Wintertime vitamin D insufficiency is common in young Canadian women, and their vitamin D intake does not prevent it," European Journal of Clinical Nutrition, vol. 55, no. 12, pp. 1091-1097, 2001.

[43] P. S. Venkataraman and B. W. Ahluwalia, "Total bone mineral content and body composition by X-ray densitometry in newborns," Pediatrics, vol. 90, no. 5 I, pp. 767-770, 1992.

[44] B. L. Specker, A. Beck, H. Kalkwarf, and M. Ho, "Randomized trial of varying mineral intake on total body bone mineral accretion during the first year of life," Pediatrics, vol. 99, no. 6, p. E12, 1997.

[45] N. F. Butte, J. M. Hopkinson, W. W. Wong, E. O. Smith, and K. J. Ellis, "Body composition during the first 2 years of life: an updated reference," Pediatric Research, vol. 47, no. 5, pp. 578585, 2000.

[46] M. Hammami, W. W. K. Koo, and E. M. Hockman, "Body composition of neonates from fan beam dual energy Xray absorptiometry measurement," Journal of Parenteral and Enteral Nutrition, vol. 27, no. 6, pp. 423-426, 2003. 


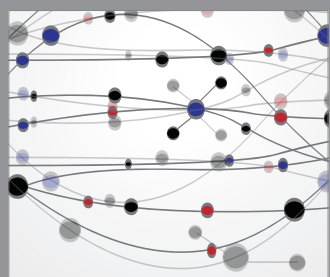

The Scientific World Journal
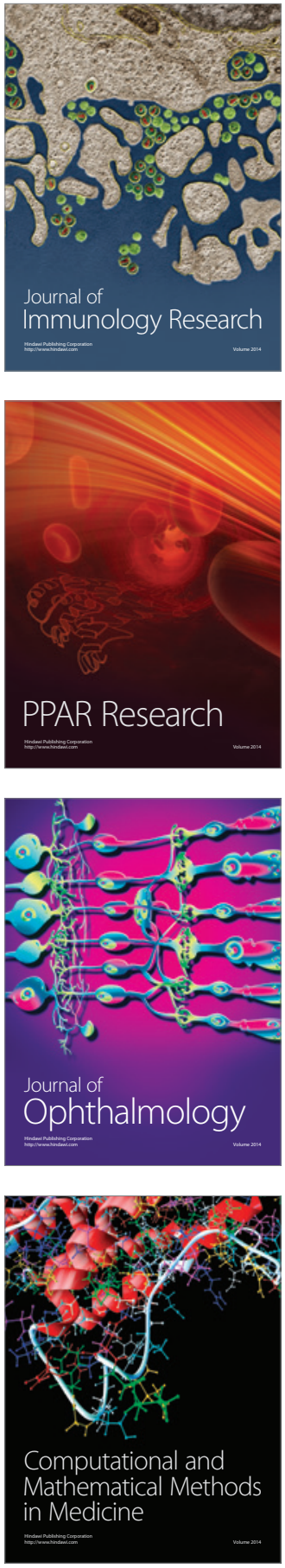

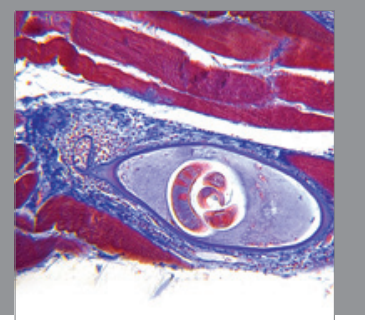

Gastroenterology

Research and Practice
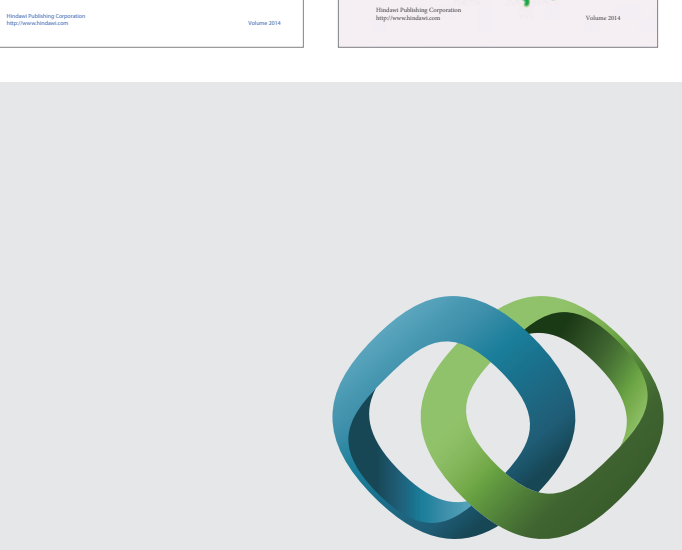

\section{Hindawi}

Submit your manuscripts at

http://www.hindawi.com
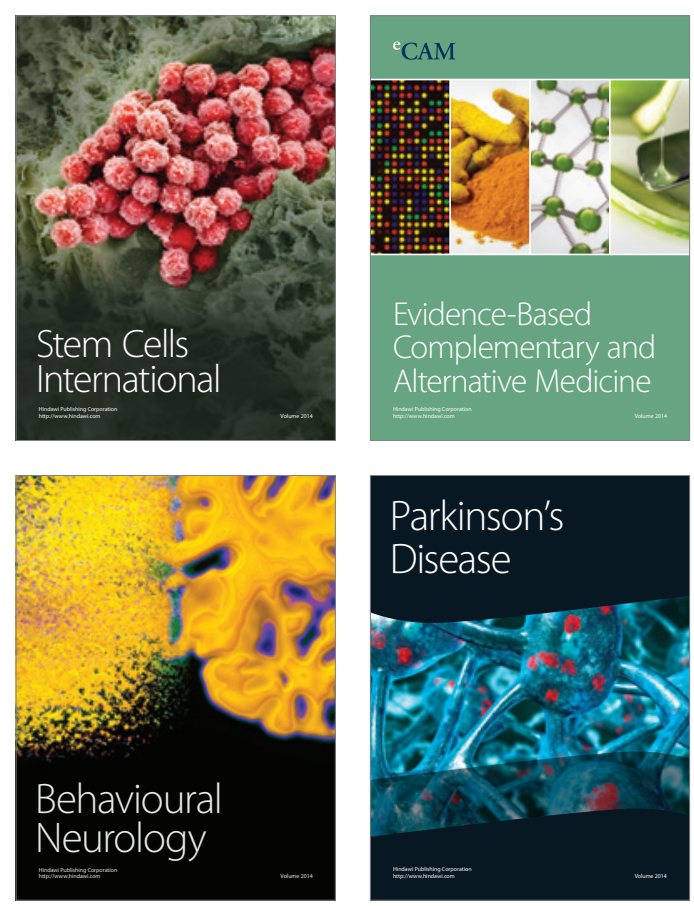

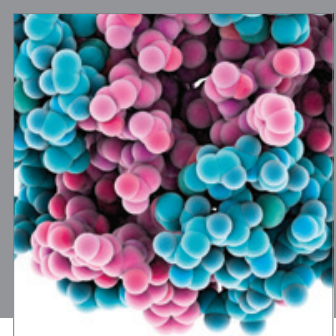

Journal of
Diabetes Research

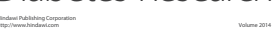

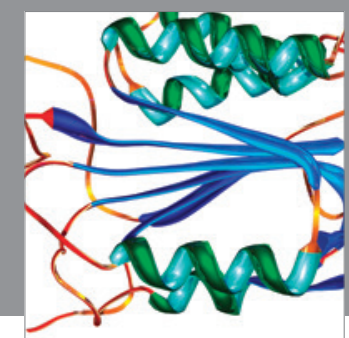

Disease Markers
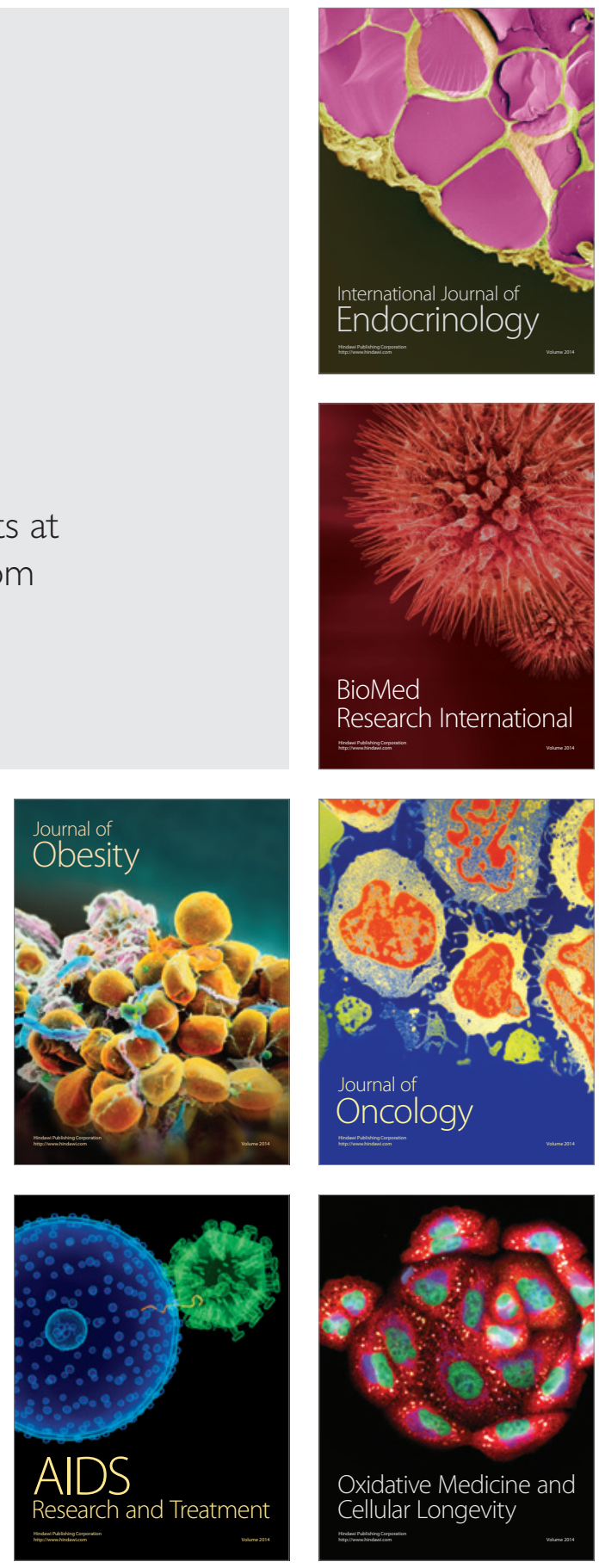